\title{
Study on Giardia duodenalis and Cryptosporidium spp. infection in veterinarians in Poland
}

\author{
Angelina Wójcik-Fatla ${ }^{1, A, D \oplus}$, Jacek Sroka ${ }^{2, A}$, Violetta Zają $c^{1, B} \oplus$, Jacek Zwoliński ${ }^{1, C} \oplus$, \\ Jacek Dutkiewicz ${ }^{1, \mathrm{E}-\mathrm{F}} \odot$ \\ ${ }^{1}$ Institute of Rural Health, Lublin, Poland \\ ${ }^{2}$ National Veterinary Research Institute, Puławy, Poland \\ A - Research concept and design, B - Collection and/or assembly of data, C - Data analysis and interpretation, \\ $D$ - Writing the article, E-Critical revision of the article, F- Final approval of article
}

Wójcik-Fatla A, Sroka J, Zając V, Zwoliński J, Dutkiewicz J. Study on Giardia duodenalis and Cryptosporidium spp. infection in veterinarians in Poland. Ann Agric Environ Med. 2018; 25(4): 732-733. doi: 10.26444/aaem/101576

\section{Abstract}

The main aim of the study was to determine the risk of two selected zoonosis infections caused by Giardia duodenalis and Cryptosporidium spp. among an occupational group of veterinarians in Poland. Two hundred and ninety-seven samples of stool were tested for the presence of Giardia cysts and Cryptosporidium oocysts using Direct Fluorescent Assay (DFA). There were no positive results for Cryptosporidium. The presence of Giardia cysts was found in two samples of faeces ( $0.67 \%)$. The risk with regard to the parasites Giardia duodenalis and Cryptosporidium spp. seems to be low among the group of veterinarians.

\section{Key words \\ Giardia duodenalis, Cryptosporidium spp., veterinarians, Poland}

\section{INTRODUCTION}

Cryptosporidiosis is a zoonosis that causes symptoms in both humans and animals [1]. It is a digestive tract invasion, and the source of infection may be an another person, food or water contaminated with parasite oocysts. Transmission of the parasite can also occur due to direct contact with infected animals. In humans, the most common species are Cryptosporidium hominis and Cryptosporidium parvum, which also cause infections in cattle, sheep and pigs [2]. Cryptosporidiosis symptoms in humans are persistent diarrhea, abdominal pain, vomiting and dehydration [3].

Giardia duodenalis is the most common intestinal parasite in humans. Worldwide, giardiasis occurs in $2-7 \%$ of the population, and in developing countries these numbers range from $20-30 \%[4,5]$. The infection occurs by consumption of Giardia cysts in contaminated water or food. In Poland, the presence of Giardia was found in surface waters (up to 61\%) $[6,7]$ and sewage (up to 84.6\%) [8]. The infection can also be acquired through direct contact with infected domestic and wild animals, such as cows, pigs, dogs, cats, sheep, goats, beavers, deer and foxes [9]. The course of giardiasis is often asymptomatic. In acute cases, diarrhea, abdominal pain, nausea, vomiting and dehydration occur. The parasite can be located in the small intestine and bile tracts, which may cause inflammation and obstruction.

\section{MATERIALS AND METHOD}

Two hundred and ninety-seven veterinarians working in district veterinary inspectorates and private veterinary clinics located in 12 provinces of Poland were examined:

Address for correspondence: Angelina Wójcik-Fatla, Institute of Rural Health, Jaczewskiego 2, 20-090 Lublin, Poland

e-mail: afatla@poczta.onet.pl

Received: 13.11.2018; accepted: 10.12.2018; first published: 17.12.2018
135 males (45.45\%) and 162 females (54.55\%); age range $\leq 30-\geq 61$. Each of the participants signed informed consent approved by the Bioethical Commission of the Institute of Rural Health (Permission No. 9/2017).

Stool samples were tested for the presence of Giardia duodenalis cysts and Cryptosporidium spp. oocysts using Direct Fluorescent Assay (DFA) (commercial test Aqua-Glo ${ }^{\mathrm{mix}}$ G/C Direct Comprehensive Kit, Waterborne Inc., USA), following by a concentration step according to Stojecki et al. [10]. Polymerase chain reaction (PCR) for positive samples in DFA was performed according to Stojecki et al. [10]. Amplicons were sequenced, and obtained sequences were analysed using Geneious R7 software and compared with those available in the GenBank database.

\section{RESULTS}

Among 297 faecal samples tested, no positive results for Cryptosporidium spp. were obtained. In DFA, the presence of Giardia cysts was found in two samples $(0.67 \%)$, from one male and one female, both aged over 61 (Fig. 1). According to the interviews by the veterinarians with positive results to Giardia, none of them reported clinical symptoms. Positive results were confirmed by PCR (Fig. 2). Sequencing confirmed amplification products as Giardia duodenalis assemblage A (sub-genotype A3).

\section{DISCUSSION}

To date in Poland, there have been only few cases of cryptosporidiosis (6 and 7 in 2016 and 2017, respectively) [11]. Many laboratories do not routinely test for Cryptosporidium in Poland, hence the incidence of the disease may be underestimated. Because the transmission risk to humans depends on the species or genotype of the parasite, the molecular 


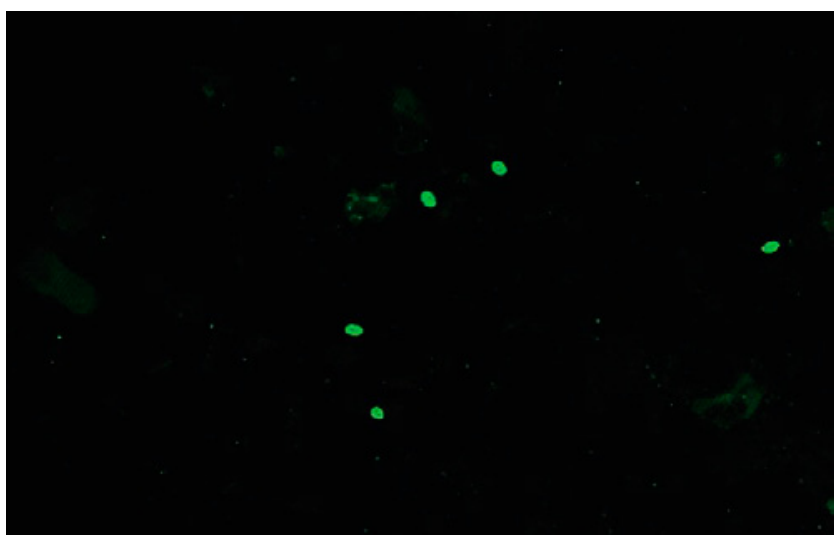

Figure 1. Example of DFA positive result. Visible Giardia cysts $\left(12 \times 10^{4} / \mathrm{g}\right.$ of stool concentration)

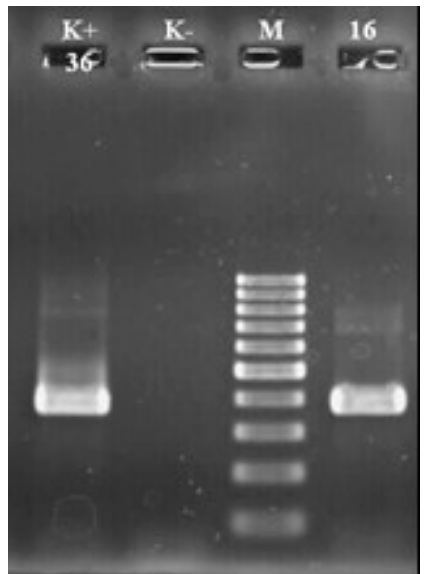

Figure 2. Example of positive result of Giardia duodenalis in PCR.

$\mathrm{K}+=$ positive control; $\mathrm{K}-=$ negative control; $\mathrm{M}$ $=$ GeneRuler 100 bp DNA Ladder; 16 = positive sample (384 bp)

characteristics of the isolates is necessary for the assessment of epidemiological risk [3]. Using the molecular methods, Benschop et al. [12] confirmed that 7 out of 156 veterinary science and veterinary technology students at Massey University in New Zealand were suffering from cryptosporidiosis. All 7 faecal specimens contained Cryptosporidium oocysts, whereas Cryptosporidium parvum IIa A18G3R1 was identified from one of the specimens. Much less is known about the risk of giardiasis among veterinarians and other occupational groups exposed to animal carriers. According to NIZP-PZH data, every year in Poland about 1,300 cases of giardiasis are recorded in humans [12], with the risk of giardiasis among children reaching $12.5 \%$ [13]. The negative results of diagnostic tests for Cryptosporidium spp. and small number of positive results for Giardia spp. could be the effect of increased awareness of veterinarians, and may be related to environmental studies focused on the occurrence of the above-mentioned pathogens. However, in literature, there are many examples of occupational exposure of veterinarians to these parasitic protozoans [14, $15,16,17]$, and for a comprehensive assessment regarding to veterinarians in Poland, further study with a larger group of participants are needed. The basic method of stool examination in the present study was DFA, PCR was used only to confirm the diagnosis. Hence, the presence of Cryptosporidium oocysts in a concentration below the limit of detection in DFA cannot be excluded

\section{Acknowledgements}

This study was supported by the Ministry of Science and Higher Education/National Centre for Research and Development coordinated by Central Institute for Labour Protection - National Research Institute, Warsaw, Poland (Agreement No. TP-54/2017/PW-PB', Project No. II.N.22: "Improving safety and working conditions", 2017-2019).

\section{Conflict of Interest Statement}

The authors declare they have no conflicts of interest.

\section{Ethical approval}

All procedures performed in studies involving human participants were in accordance with the ethical standards approved by the Bioethical Commission of the Institute of Rural Health in Lublin (Permission No. 9/2017).

\section{REFERENCES}

1. Hunter PR, Thompson RC. The zoonotic transmission of Giardia and Cryptosporidium. Int J for Parasitol. 2005; 35: 1181-1190.

2. Xiao L, Feng Y. Zoonotic cryptosporidiosis. FEMS Immunol Med Microbiol. 2008; 52: 309-323.

3. Ramirez NE, Ward LA, Sreevatsan S. A review of the biology and epidemiology of cryptosporidiosis in humans and animals. Microbes Infect. 2004; 6: 773-785.

4. Marshall MM, Naumovitz D, Ortega Y, Sterling CR. Waterborne protozoan pathogens. Clin Microbiol Rev. 1997; 10: 67-85.

5. Gelanew T, Lalle M, Hailu A, Pozio E, Cacciò SM. Molecular characterization of human isolates of Giardia duodenalis from Ethiopia. Acta Trop. 2007; 102: 92-99.

6. Sulima P, Werner A, Majewska AC. Occurrence of Giardia cysts, Cryptosporidium and Cyclospora oocysts in surface water pools in Poznań district. VIII European Multicolloquium of Parasitology (EMOP). Acta Parasitol. 2000; 45: 212.

7. Sroka J, Giżejewski Z, Wójcik-Fatla A, Stojecki K, Bilska-Zając E, Dutkiewicz J, Kochanowski M. Potential role of beavers (Castor fiber) in contamination of water in the Masurian Lake District (north-eastern Poland) with protozoan parasites Cryptosporidium spp. and Giardia duodenalis. Bull Vet Inst Pulawy. 2015; 59: 219-228.

8. Sroka J, Stojecki K, Zdybel J, Karamon J, Cencek T, Dutkiewicz J. Occurrence of Cryptosporidium oocysts and Giardia cysts in effluent from sewage treatment plant from eastern Poland. Ann Agric Environ Med. 2013; 1: 57-62.

9. Heyworth MF. Giardia duodenalis genetic assemblages and hosts. Parasite. 2016; 23: 13.

10. Stojecki K, Sroka J, Cencek T, Dutkiewicz J. Epidemiological survey in Łęczyńsko-Włodawskie Lake District of eastern Poland reveals new evidence of zoonotic potential of Giardia intestinalis. Ann Agric Environ Med. 2015; 22(4): 594-598.

11. Annual Report of Infections with Selected Infectious Diseases in Poland from 1 January to 31 December 2017 and in the Comparable Period of 2016. National Institute of Public Health, Department of Epidemiology and Surveillance of Infectious Diseases, Laboratory of Monitoring and Epidemiological Analysis, Warsaw, Poland. http://wwwold.pzh.gov.pl/ oldpage/epimeld/2017/INF_17_12B.pdf Accessed October 29, 2018.

12. Benschop J, Booker CM, Shadbolt T, Weston JF. A Retrospective Cohort Study of an Outbreak of Cryptosporidiosis among Veterinary Students. J Vet Sci. 2017; 4: 29.

13. Plutzer J, Lassen B, Jokelainen P, Djurković-Djaković O, Kucsera I, Dorbek-Kolin E, Karanis P. Review of Cryptosporidium and Giardia in the eastern part of Europe, 2016. Euro Surveillance 2018: 23.

14. Epp T, Waldner C. Occupational health hazards in veterinary medicine: physical, psychological, and chemical hazards. Can Vet J. 2012; 53(2): 151-157.

15. Chethan Kumar HB, Lokesha KM, Madhavaprasad CB, Shilpa VT, Karabasanavar NS and Kumar A. Occupational zoonoses in zoo and wildlife veterinarians in India. Vet World. 2013; 6(9): 605-613.

16. Bonini S, Buonacucina A, Selis L, Peli A, Mutti A, Corradi M. Occupational hazards in veterinarians: an updating. Veterinar Sci Techno. 2016; 7: 3.

17. Fowler HN, Holzbauer SM, Smith KE, Scheftel JM. Survey of occupational hazards in Minnesota veterinary practices in 2012. Am Vet Med Assoc. 2016; 15; 248(2): 207-218. 